\title{
Imaging ground surface deformations in post-disaster settings via small UAVs
}

\author{
Richard L. Ybañez ${ }^{1 *} \mathbb{0}$, Audrei Anne B. Ybañez ${ }^{2}$, Alfredo Mahar Francisco A. Lagmay ${ }^{1,2}$ and Mario A. Aurelio ${ }^{1}$
}

\begin{abstract}
Small unmanned aerial vehicles have been seeing increased deployment in field surveys in recent years. Their portability, maneuverability, and high-resolution imaging are useful in mapping surface features that satellite- and planemounted imaging systems could not access. In this study, we develop and apply a workplan for implementing UAV surveys in post-disaster settings to optimize the flights for the needs of the scientific team and first responders. Three disasters caused by geophysical hazards and their associated surface deformation impacts were studied implementing this workplan and was optimized based on the target features and environmental conditions. An earthquake that caused lateral spreading and damaged houses and roads near riverine areas were observed in drone images to have lengths of up to $40 \mathrm{~m}$ and vertical displacements of $60 \mathrm{~cm}$. Drone surveys captured 2D aerial raster images and 3D point clouds leading to the preservation of these features in soft-sedimentary ground which were found to be tilled over after only 3 months. The point cloud provided a stored 3D environment where further analysis of the mechanisms leading to these fissures is possible. In another earthquake-devastated locale, areas hypothesized to contain the suspected source fault zone necessitated low-altitude UAV imaging below the treeline capturing Riedel shears with centimetric accuracy that supported the existence of extensional surface deformation due to fault movement. In the aftermath of a phreatomagmatic eruption and the formation of sub-metric fissures in nearby towns, highaltitude flights allowed for the identification of the location and dominant NE-SW trend of these fissures suggesting horst-and-graben structures. The workplan implemented and refined during these deployments will prove useful in surveying other post-disaster settings around the world, optimizing data collection while minimizing risk to the drone and the drone operators.
\end{abstract}

Keywords: Natural hazards, Post-disaster, Small UAV

\section{Introduction}

Disasters caused by earthquakes and volcanic eruptions regularly impact large areas at significant cost to lives and infrastructure. Furthermore, fissures, landslides, subsidence, and lateral spreading are post-disaster ground surface deformations that both continue to pose a hazard to populated areas as well as serve as key surface data for the understanding of the hazard processes that caused the disaster in the first place. Apart from humanitarian

\footnotetext{
*Correspondence: rich.ybanez@nigs.upd.edu.ph

${ }^{1}$ National Institute of Geological Sciences, College of Science, University

of the Philippines, Diliman, 1101 Quezon City, Philippines

Full list of author information is available at the end of the article
}

and medical first-responders, quick-response teams composed of geoscientists must also be deployed to these post-disaster sites to study the affected area for hazard processes that have happened and may still happen. The post-disaster setting is typically more difficult to carry out surveys and other scientific activity in due to the still-dangerous conditions of the area as well as having to navigate the on-going humanitarian crisis on-site. Implementation of a prepared workplan for such an event may help scientists and responders to be more prepared for responding quickly for data collection and analysis.

Unmanned aerial vehicles (UAV), or more commonly known as drones, have seen expanded use in the last few years in numerous industries and fields such as
Springer Open

(c) The Author(s) 2021. This article is licensed under a Creative Commons Attribution 4.0 International License, which permits use, sharing, adaptation, distribution and reproduction in any medium or format, as long as you give appropriate credit to the original author(s) and the source, provide a link to the Creative Commons licence, and indicate if changes were made. The images or other third party material in this article are included in the article's Creative Commons licence, unless indicated otherwise in a credit line to the material. If material is not included in the article's Creative Commons licence and your intended use is not permitted by statutory regulation or exceeds the permitted use, you will need to obtain permission directly from the copyright holder. To view a copy of this licence, visit http://creativeco mmons.org/licenses/by/4.0/. 
agriculture, infrastructure, media productions, leisure, and scientific research (Greenwood et al. 2020). Their ease-of-use, portability, and ever-improving imaging capabilities offer a wide range of applications, including mapping of surface features. Their high-resolution cameras and flight altitude often result in 2D images and 3D maps that are more detailed and accurate than satellite imagery (Sharma 2016). This, combined with the preservation of perishable data in a post-disaster scenario, makes the swift deployment of small UAVs essential in assessing the effects of the disaster (Gomez \& Purdie 2016). While the scope of geohazards is broad, the three hazards that have seen the most application and deployment of UAV technology and research in recent years are earthquakes, volcanic eruptions, and landslides.

In 2014, Xu et al. (2014) implemented an unmanned aircraft system for the acquisition and processing of drone data in the aftermath of a disaster. Satellite images may not be available in the days after a disaster when assessment of damage is most crucial in preventing more human and economic loss. Existing technology and equipment allow for acquisition of data independent of ground control points and relying solely on Global Positioning System (GPS) satellites whereas processing of acquired images can be done in the field with the pertinent software. Mission planning, acquisition, data validation, and data consolidation can be done entirely in the field ensuring adaptability to the dynamic situation on the ground in a post-disaster scenario.

In the aftermath of the 2015 Nepal Earthquake, fixedwing UAVs were deployed to assess structural damage in the Kathmandu valley in tandem with traditional helicopter overflights (Inoue et al. 2016). While successfully surveying in at least four damaged towns, restrictions included time windows and months-long approval process from the local government. These considerations must be studied when planning flights, even in a postdisaster scenario. Local restrictions are not necessarily loosened in the event of a disaster.

Acquired UAV imagery and the assessment of postdisaster damages from the resulting orthomosaics are products that can be used as input in other Geographic Information System (GIS) analyses such as overlay analysis and point density mapping. Drone-acquired imagery from the $2017 \mathrm{Mw} 6.3$ earthquake in Lesvos, Greece, was correlated with the area's relief and underlying geology to delineate the distribution of damaged structures (Mavroulis et al. 2019). Despite differences in the material and design of different houses, clustering of damaged structures had a perceivable trend towards the half of the town underlain by alluvial deposits as compared to the other half underlain by fluvial sediments and sedimentary rocks.
In this study, we outline a workplan for the conduct of UAV-assisted assessment surveys in a post-disaster setting in the aftermath of three disasters in the Philippines in 2019 and 2020 caused by natural hazards to assess the location, distribution, and trends of these surface deformations that would provide data for the broader regional analysis of the source event's characteristics, processes, and mechanics. We demonstrate how this workplan was able to guide flight plans and data gathering in post-disaster settings, the type and quality of data that was produced from these imaging flights, and the immediate and medium-term advantages of using this highly portable imaging system in the context of hazards impact analysis and assessment. Moreover, the deployment of small UAVs to disaster-stricken areas by field teams outpaces satellite-based remote sensing platforms which are also being used to rapidly assess impacted regions with drones supplying immediate imagery as opposed to remotely sensed products that take days to download and process (Xu et al. 2014).

The 22 April 2019 Central Luzon Earthquake was triggered by a Mw 6.1 earthquake at $10 \mathrm{~km}$ depth with an epicenter located $18 \mathrm{~km}$ east of Castillejos, Zambales (PHIVOLCS 2019a). Nearby known active faults are the Philippine Fault, Iba Fault, East Zambales Fault and Manila Trench which are the main generators in the area. Very strong to strong ground shaking was experienced in the adjacent and nearby provinces of Bataan, Pampanga, Bulacan, and Metro Manila which resulted in 16 casualties, 86 injured, and 14 missing persons as well as at least 80 damaged structures in the affected areas (National Disaster Risk Reduction and Management Council 2019; PHIVOLCS 2019a). Landslides and liquefaction, manifested by sand boils and lateral spreading, were observed, and reported in several areas, particularly in the hilly and deltaic areas, respectively, of Zambales and Pampanga.

The October 2019 Cotabato Earthquakes was a series of four strong earthquakes of Mw 6.1 to 6.6 that occurred within the vicinity of Makilala, Cotabato from 16 to 31 October 2019 (PHIVOLCS 2019b). The Mw 6.3 earthquake was located $22 \mathrm{~km}$ southeast of Tulunan, Cotabato with a depth of $8 \mathrm{~km}$ whereas the Mw 6.1 and 6.3 earthquakes on 29 October have an epicenter located $25 \mathrm{~km}$ southeast of Tulunan and a depth of $7 \mathrm{~km}$. Lastly, the 31 October earthquake had a shallow depth of $2 \mathrm{~km}$ and an epicenter near Tulunan, Cotabato (PHIVOLCS 2019b). Landslides, tension cracks, ground fissures, and liquefaction were reported in numerous towns surrounding the epicenters of the earthquakes. $\mathrm{Li}$ et al. (2020) consider this earthquake sequence as the result of the rupturing of conjugate faults reacting to an $\mathrm{E}-\mathrm{W}$ directed regional compressional stress in southern Philippines. There were 23 reported casualties, 563 
injured, 11 missing, and nearly 50,000 structures damaged as a result of these earthquakes (National Disaster Risk Reduction and Management Council 2020a).

The 12 January 2020 Taal Volcano phreatomagmatic eruption resulted in a $15-\mathrm{km}$-high ash column that rained heavy ashfall on the surrounding towns (Laurel 2020; PHIVOLCS 2020a). The Taal eruption occurred in the afternoon following a series of phreatic explosions which progressed to a large phreatomagmatic eruption late in the afternoon. Nearly 750,000 people were displaced or affected by the resulting ashfall (National Disaster Risk Reduction and Management Council 2020b). Several fissures were reported in towns surrounding Taal Lake southwest of Taal Volcano dealing damage to houses and other infrastructure (PHIVOLCS 2020b). Using InSAR analysis, Bato et al. (2020) associates this volcanic activity that involved magma expulsion and fissure formation to lateral dike emplacement.
In all three disaster events, small UAVs were deployed to facilitate rapid assessment of ground deformation processes on nearby relief and built-up areas to preserve the orientation, appearance, and distribution of these deformation features, as well as to obtain actionable data on evacuation, resettlement, and mitigation (Fig. 1). Furthermore, the UAV images obtained were and will be used as reference for more detailed studies such as analysis of lateral spreading phenomena in the riverine areas in Pampanga, Shallow Seismic Reflection surveys of potential fault zones in Cotabato, and mapping and analysis of fissures in communities around Taal Volcano Island and Taal Lake.

\section{UAV deployment and workplan}

Two quadcopter UAVs were used during these three events: the DII Mavic 2 Pro and the DJI Mavic Air. Both UAVs feature a compact foldable design making transport and deployment relatively easy. The Mavic 2 Pro
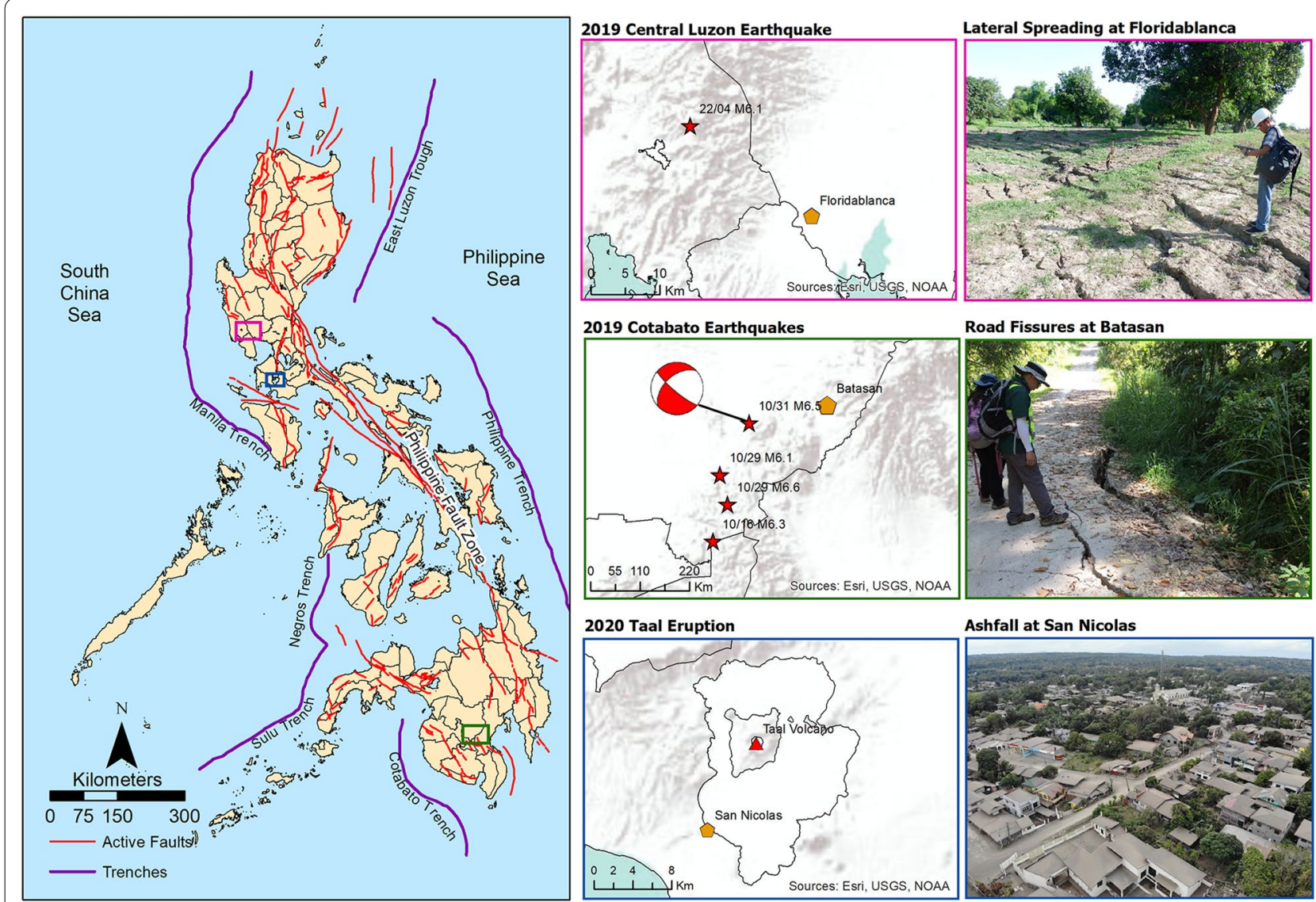

Fig. 1 Location map of the three disaster events: the 2019 Central Luzon earthquake in pink boxes, the 2019 Cotabato earthquakes in green boxes, and the 2020 Taal eruption in blue boxes. The earthquake epicenters are symbolized by red stars and labeled with their dates and magnitudes. Taal Volcano's main crater is indicated by a red triangle. Points of observation for the effects of these hazards are indicated by orange markers in their maps with corresponding images at the right-most column of the figure. The Focal Mechanism Solution for the last earthquake in the 2019 Cotabato Earthquakes is also included 
was primarily used due to its superior camera and flight time. This model is equipped with the L1D-2c Hasselblad camera with a 20-megapixel 1 " sensor and with a field of view of about $77^{\circ}$, aperture of $\mathrm{f} / 2.8-\mathrm{f} / 11$ and shooting range. Flight time is rated at $25 \mathrm{~min}$ of normal use (DJI 2020). The Mavic Air served as a backup UAV and features a less-powerful 12-megapixel camera with a $1 / 2.3^{\prime \prime}$ sensor and a flight time of $20 \mathrm{~min}$ (DJI 2018). The drone controllers were attached to an iPad mini or an Android phone, depending on the situation, and loaded with the DJI controller app, the Pix4D app, and the Ctrl+DJI app which ties the two apps together on an Android device. The Pix4D app on iOS, while being more stable than its Android counterpart, does not include a feature to load shapefiles or project-based mission planning where multiple flights can be found on one window.

The option to load shapefiles and plan multiple flight missions on a single map is crucial when surveying a target area efficiently and quickly. In the search for a fault rupture in the 2019 Cotabato Earthquakes, shapefiles containing early and initial interpretations from deformation maps from satellite imagery were used as guides for locating areas of interest for drone imaging missions. Figure 2 shows the inferred fault trace from remotely sensed data represented as a red shapefile loaded unto the Pix4D flight planning Android app providing guidance for optimized multi-mission flight plans that can cover the largest possible are of interest in the least number of flights.

Flight parameters must be adjusted on-the-fly depending on environmental conditions and the size and extent of surface features to be mapped and captured in the field. A default flight altitude is set by Pix4D at $50 \mathrm{~m}$ above the surface: a reasonable elevation for avoiding tall

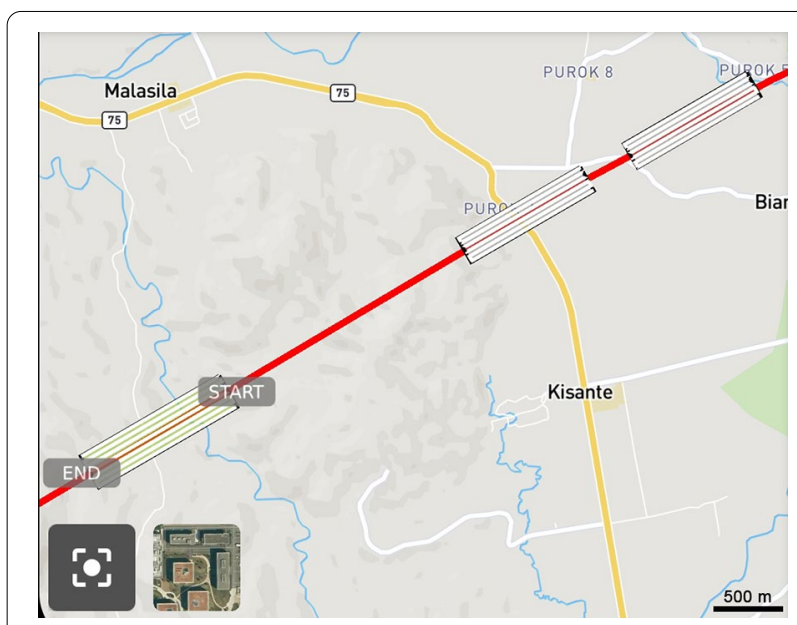

Fig. 2 Shapefiles of possible fault trace (red) derived from initially generated interferograms and projected flight plans (green and gray boxes) loaded on Pix4Dcapture flight planning app trees and structures in relatively flat terrain but still low enough to capture centimetric surface features such as cracks and fractures caused by lateral spreading. Where obstacles are absent, flight elevation can be reduced to 10 to $20 \mathrm{~m}$ to obtain very high-resolution imagery of the surface features. Where surface deformations cover a larger area which need to be surveyed, elevations of $100 \mathrm{~m}$ can be reached with surface features still observable.

Two flight modes can be used in conducting surveys: manual and automatic. The automatic flight mode is generated by the flight planning feature of the Pix 4D app where a specified target area for image acquisition is selected for the map and the software automatically sets the flight path covering the entire area in consideration of the set flight altitude and image overlap percentage. Once the flight is started, the Pix4D app forwards the flight plan to the DJI controller app which carries out the flight automatically. The manual flight mode may be necessary where obstacles are present in the drone's flight path such as trees and structures, particularly when the flight elevation is lower than Pix4D's minimum automated flight altitude of $10 \mathrm{~m}$. The drone operator must avoid possible obstacles while manually activating the drone's camera and ensuring that an adequate overlap is attained for the orthomosaic processing.

While the Pix4D manual and other UAV flight guidelines state that line-of-sight and UAV visibility must be always maintained, it may be necessary to fly the drone beyond these parameters in a post-disaster setting if impacted or deformed areas must be assessed while keeping the drone pilot and field team in relative safety. As such, distances between the take-off point and the survey grid start point could be as much as $1 \mathrm{~km}$, and the end point, or farthest point at $3 \mathrm{~km}$. The DII manual indicates signal connection between the controller and the drone could be maintained at distances of up to $7 \mathrm{~km}$. However, based on the experience of the researchers in the three deployments in this study, distances of beyond $3 \mathrm{~km}$ result in rapid signal degradation and potential loss of the drone in semi-urban and rural settings. Interference from houses, electric lines, and other urban structures are the likely reason for this diminished signal range in such locations and must be taken into account when planning survey grids (DJI 2020).

There are two considerations in a post-disaster scenario when finding the optimal setting for the image overlap: the need for an accurate 3D point cloud and the amount of time it will take for the flight and by extension the battery consumption. A lower image overlap of around 20-30\% will result in fewer flyovers, faster flight time, and less battery consumption. In a post-disaster scenario where the ability to recharge batteries is dictated by the availability of power and time is a crucial resource for 
surveying as large an area as possible, a low image overlap setting is ideal. This low overlap, however, is just enough for generating a 2D orthomosaic of the study area with tie-points too few for generating a $3 \mathrm{D}$ point cloud. Where a $3 \mathrm{D}$ point cloud is necessary, such as when there is a need to capture and preserve ground deformation for subsequent analysis, an image overlap of $60-80 \%$ is preferred to capture the necessary number of tie-points for the software to generate a point cloud. However, further emphasis is placed on the increased battery consumption of high-overlap flights. As such, the objectives of each flight must be pre-planned to maximize flight time and data acquisition for the desired products.

The acquired images from automated flights can be processed into an orthomosaic, digital surface model (DSM), and 3D point cloud through the Pix4D cloud service, Pix4D Desktop interface, or similar third-party drone processing software (Fig. 3). The manual flight from this study's post-disaster assessment was processed through ESRI ArcGIS Pro's Ortho Mapping module.

Pre-deployment and on-site phases of surveys are highly dependent on several conditions and parameters (Fig. 4). The data requirement and workflow exhibits the necessary strategic planning for disasters. Remotely sensed post-disaster data, where available, provides spatial constrains and priority areas for assessing the effects of the natural hazard. For large-scale, high-magnitude hazards such as earthquakes, this is useful in determining the highest priority areas for surveying within a very large disaster-stricken area. Terrain and hazard maps provide additional guidance for accessibility and possible locations of mappable ground deformation features. Finally, local reports provide the best data for the locations of target areas as well as where assessment is most needed in response to evacuation and resettlement requirements.

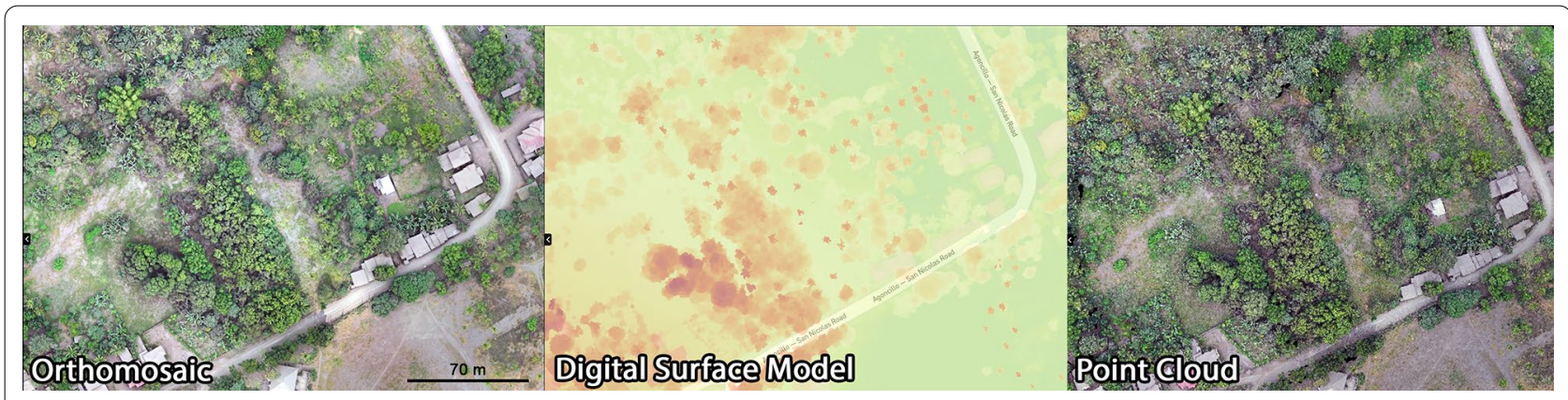

Fig. 3 Three types of output from a 2-dimensional mapping mission with a high measure of image overlap at 60\%

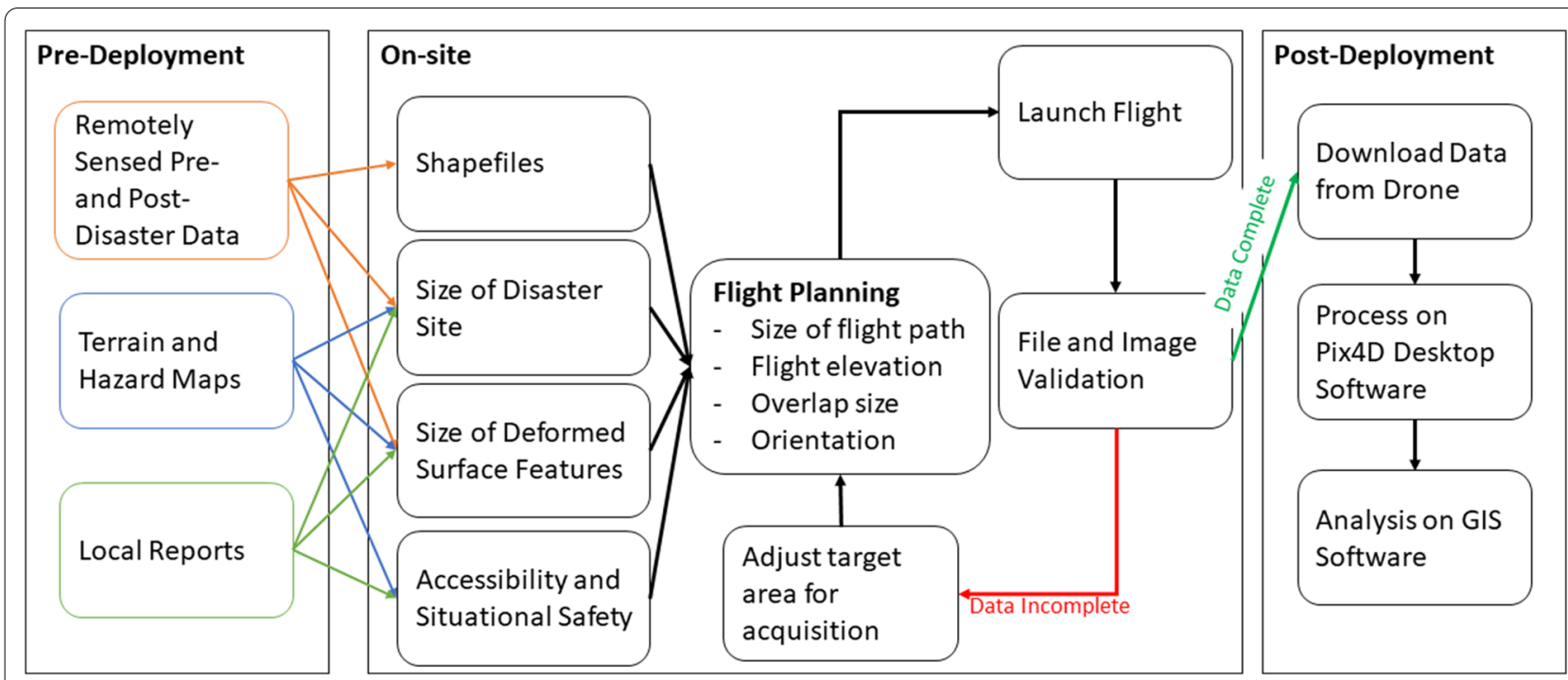

Fig. 4 Data requirements and workplan for conducting UAV surveys in a post-disaster setting 


\section{Results and discussion}

\section{Central Luzon earthquake}

In the aftermath of the 2019 Central Luzon Earthquake last 22 April 2019, the mayor of Floridablanca, Pampanga requested for geological assessment of several fissures that damaged houses in fear that these fissures mark the trace of an active fault and would therefore be earthquake-generating. Northeast-trending fissures with individual lengths of approximately 5 to $10 \mathrm{~m}$ affecting a total length of approximately $170 \mathrm{~m}$ were found to be consistently dropping downslope to the southeast by $30 \mathrm{~cm}$ towards a topographic low identified to be dried-out riverbed being used as cropland. These fissures appear as linear while some are arcuate in shape in Quaternary alluvium. During earthquakes, the ground lowers or subsides due to ground shaking. Lateral spreading or rock spread is the lateral displacement of sloping ground because of pressure build-up in the surface deposits during occurrences of ground shaking (Hungr et al. 2014).

One segment of these fissures passing through approximately 15 houses is shown in Fig. 5. This orthomosaic was generated from images captured from $50 \mathrm{~m}$ above the ground with adequate resolution for recording the location and extent of the fissures. The trend of the fissures is parallel to the ephemeral stream to the southeast, indicating a lateral spreading process along the riverbank. The vertical displacements of these fissures are noticeably more prominent towards the stream, starting at sub-cm measurements at the farthest point and measuring up to $30 \mathrm{~cm}$ nearest the stream (Fig. 5, inset).

In another part of the river downstream, more occurrences of lateral spreading were found to affect farmland (Fig. 6). The fissures trend to the north-northeast, following the more northward trend of the dried-out stream which is, in this location, still used as farmland. The surface deformation in this area is characterized by two different occurrences: the first being along the gently sloping riverbank leading into the dried-out river and the second being on the dried-out river itself. Along and above the riverbanks, fissures extended to about $40 \mathrm{~m}$ in length, deformed an area $30 \mathrm{~m}$ measured perpendicularly from the riverside, and displaced the surface vertically by at the most $60 \mathrm{~cm}$.

These images were acquired from a flight elevation of $50 \mathrm{~m}$ and an overlap of $80 \%$ resulting in a spatial resolution of $1.17 \mathrm{~cm}$. Six months later, the area has been re-tilled and new crops have been planted removing all evidence of the widespread lateral spreading that occurred there in the months prior (Fig. 6C). The immediate collection of UAV imagery in the days after the disaster allowed for the digital preservation of these features for subsequent study and analysis of formation patterns and mechanisms of fissures in sedimentary basins.

A road in a different area of Pampanga was also found to have collapsed rendering it impassable. Figure 7A shows the orthomosaic of the north-trending road with

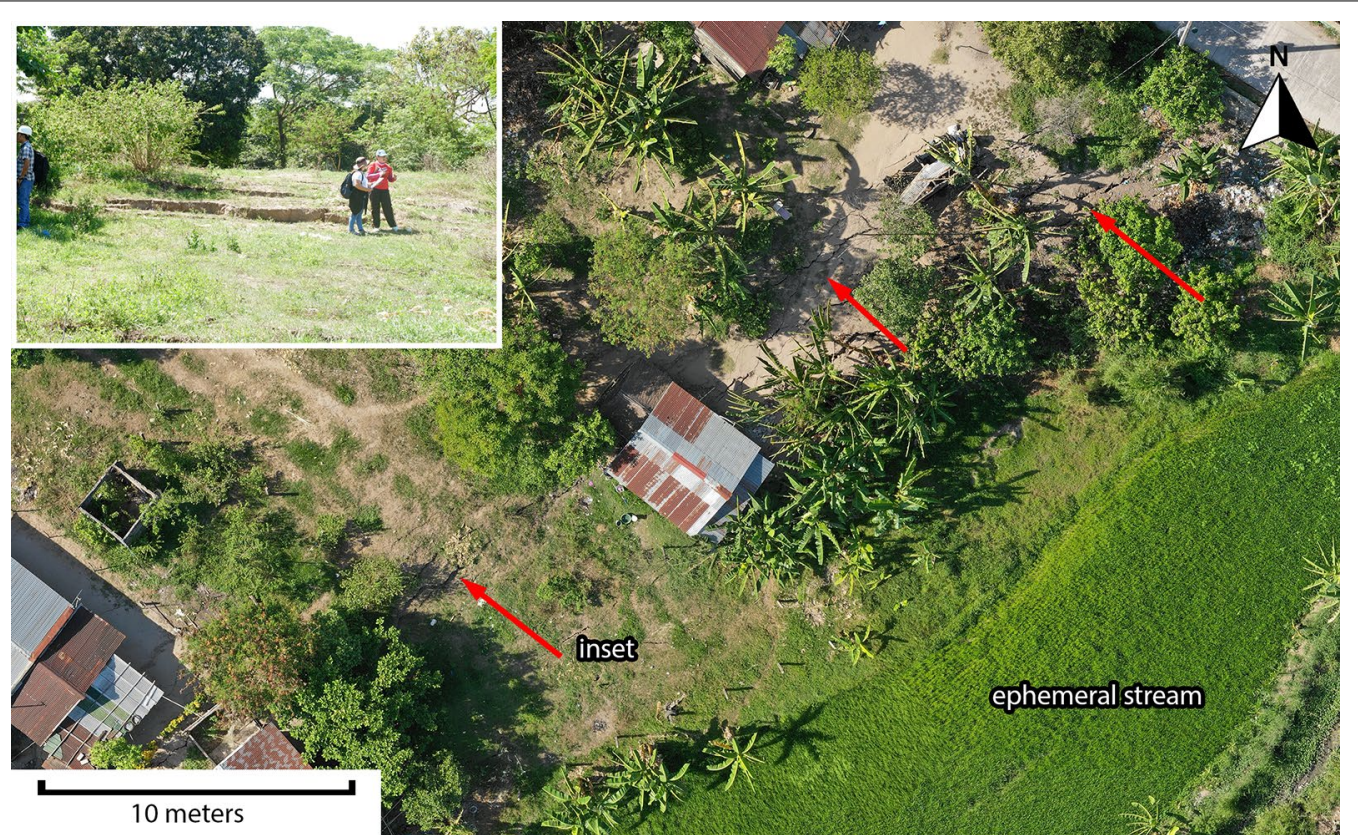

Fig. 5 Northwest-trending fissures as a result of lateral spreading (pointed by red arrows) induced by ground shaking. Inset shows on-ground image of fissure and a vertical drop of approximately $30 \mathrm{~cm}$ 


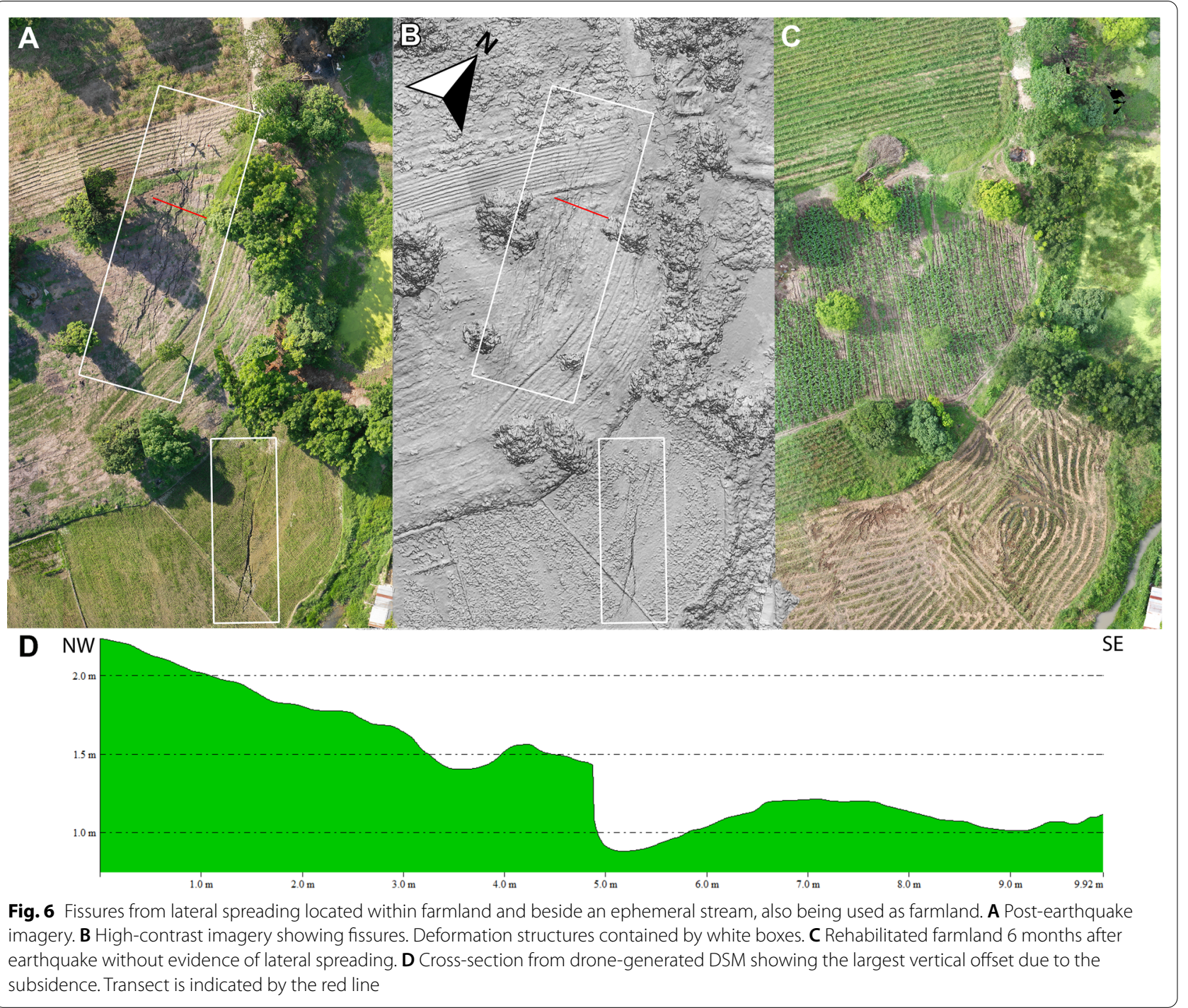

its western half collapsing into dried-out wetlands while the eastern half remains considerably intact despite also being bound by a stream. The scale of the collapse of this road highlights the need for improved construction to account for the wetland terrain surrounding it. Figure 7B shows the same area in a 3D point cloud with the westward orientation of the collapsed blocks preserved by the model. Based on the point cloud and DSM, block sections of the road as high as $4 \mathrm{~m}$ high collapsed into the dried-out wetlands to the west with up to $150 \mathrm{~m}$ of road being affected. Fissures observed in Pampanga after the Central Luzon earthquake are related to sedimentological and hydrological changes in the basin. The formation of fissures in the area poses a geologic hazard that must be acknowledged and mapped since these may cause further damage in the future along the riverside communities of Pampanga.

\section{Cotabato earthquakes}

During the October 2019 Cotabato Earthquakes, UAV flights were used as one of the methods in searching for an undiscovered fault trace suspected to be the source of the last of the 4 earthquakes, a M 6.5 occurring on 31 October. The UAV provided information that otherwise would not have been obtained from images gathered by satellite missions or from conventional airborne survey techniques. One such occurrence on-site for UAV flights was searching for landslides and a potential fault scarp. Towards the middle of the inferred fault segment, a huge landslide which flowed west-southwest was found atop a north-south trending ridge (Fig. 8). Dense vegetation throughout the study area hampered data collection of high-altitude UAV flights. In the processed orthomosaic, the landslide is barely perceptible only evidenced by the lightly colored freshly exposed 


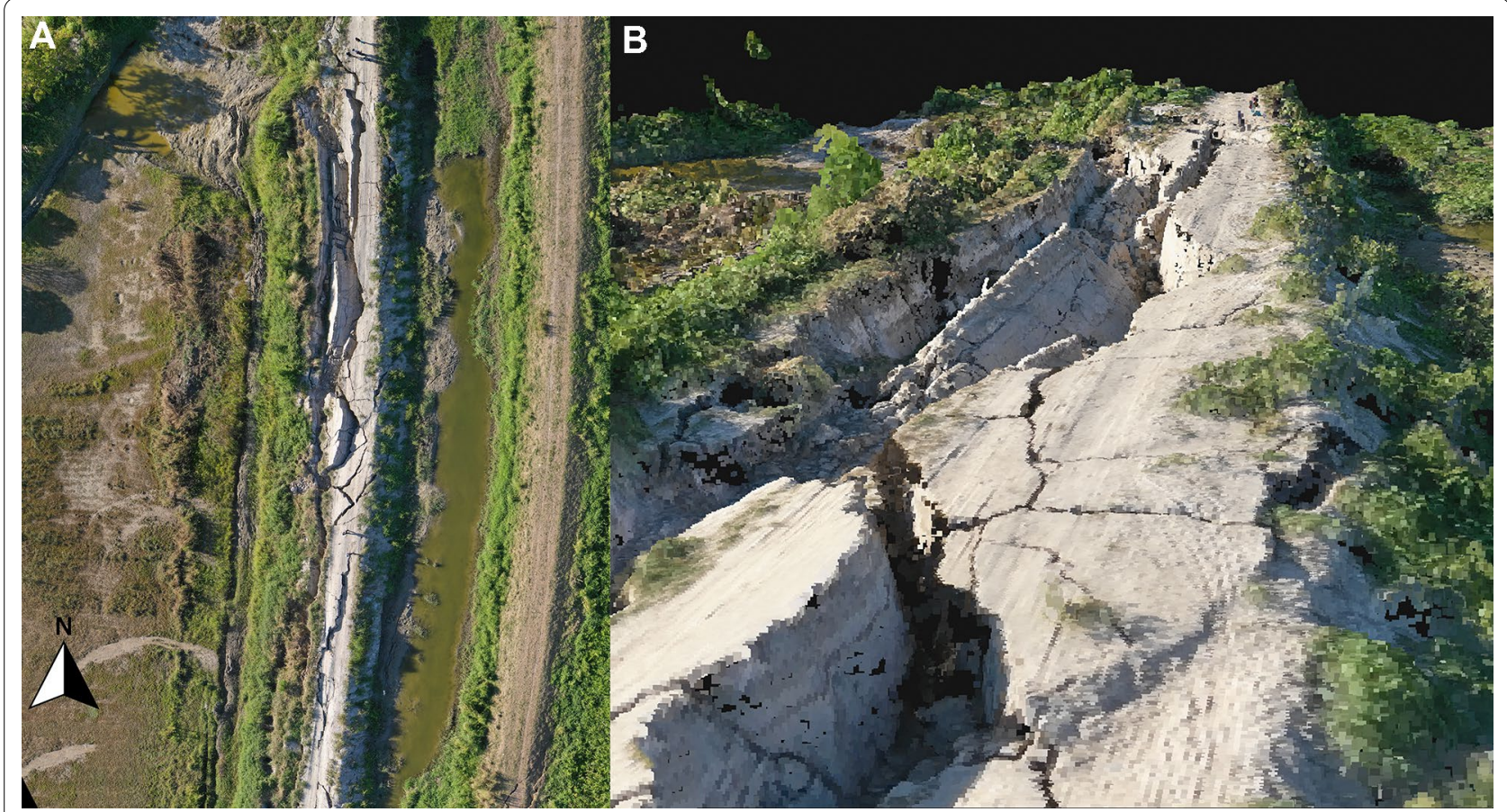

Fig. 7 Collapsed road in Central Luzon as a result of ground shaking. A Plan-view based on orthomosaic imagery. B Oblique view of 3-dimensional point cloud

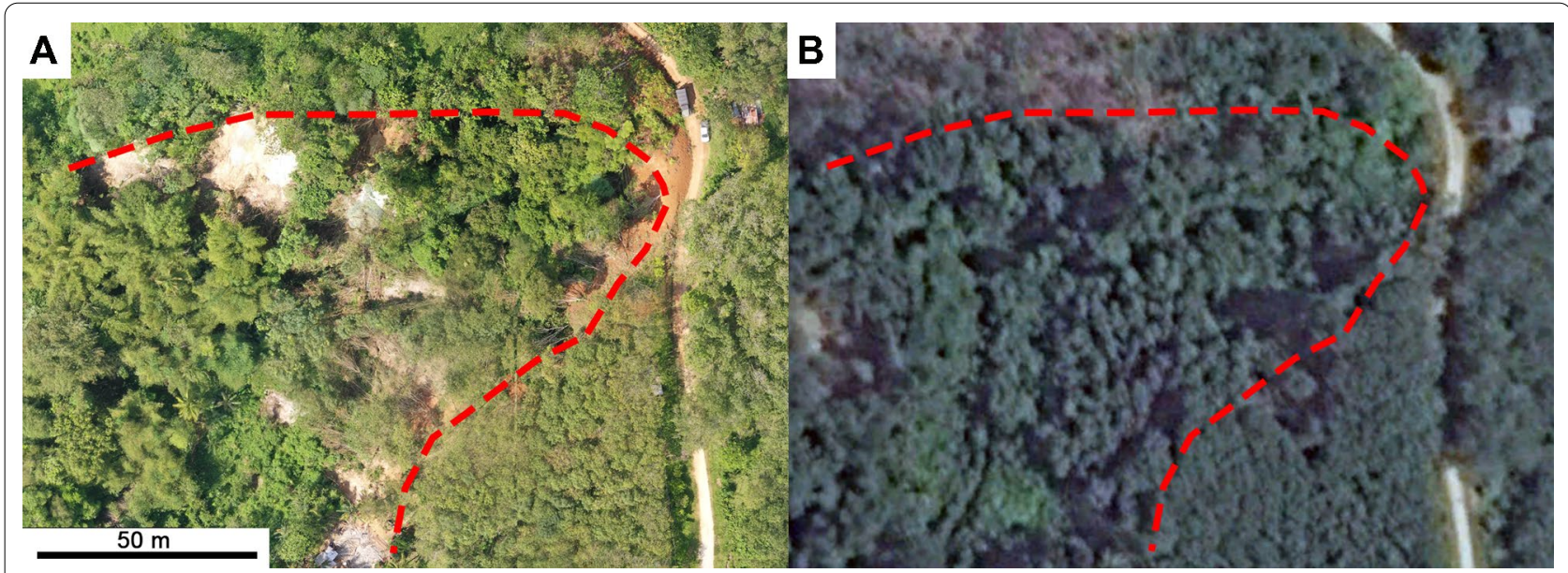

Fig. 8 A Landslide obscured by thick vegetation (red dashed line). Extent validated on the ground and characterized in drone imagery by light-colored freshly exposed soil and slanting trees. B Google Earth imagery taken Sept. 2016 of the same area showing the lack of a landslide scarp. The southern edge of the landslide scarp follows the curved elevated tree line

soil as well as trees near the head scarp leaning towards the direction of the landslide. Figure 8B shows historical imagery available on Google Earth taken in September of 2016 where there is no evidence of exposed soil or a landslide scarp. The landslide scarp's curvature towards the southern end is seen to follow the tree line shadow that curves in the same way indicating a ridge or change in relief that the landslide followed.

Preliminary and initial analysis of pre- and post-earthquake Interferometric Synthetic Aperture Radar (InSAR) time series images suggested the presence of NE-SW trending deformation zone centered at the epicenter of 
the Mw 6.5 tremor of 31 October 2019 in the village of Biangan, in the northern sector of Makilala town. The east-west trending Riedel shears suggesting dextral faulting, consistent with the focal mechanism solution consistently indicating a dextral solution along the NE-SW trending nodal plane (Ekström et al. 2012) of the associated event, and the interference pattern inferred from InSAR data (Li et al. 2020).

Individual shears were observed at lengths of about 1 to $2 \mathrm{~m}$ stretching across a zone of about $50 \mathrm{~m}$ in flat farmland. The dense and tall vegetation, composed of coconut trees, as well as the sub-meter scale of the Riedel shears necessitated a manual low-altitude flight below the treeline while avoiding collision with coconut trees. Relying on its capability to fly at low altitudes and hence ability to obtain high-resolution images with centimetric accuracy, a UAV survey over the suspected trace of a NE-SW fault confirmed the presence of E-W-oriented, metric scale, en echelon cracks arranged along a NE-SW trending zone about a kilometer long.

The result is a patchwork of manually shot images at a flight altitude of $4 \mathrm{~m}$ above ground level following a roughly northeast-southwest trending flight path (Fig. 9). The resulting orthomosaic formed from the low-altitude flight reveals the high-resolution preservation of the east-west en echelon fissures from Riedel shears, which support the hypothesis of a NE-trending dextral fault in the volcaniclastic region which were missed out in earlier attempts to find a ground surface rupture.

These E-W en echelon fissures in the surface captured by the UAV were used as an impetus for investigating the subsurface fault and surface field mapping. A high-resolution shallow seismic reflection survey was conducted one month after with the imaged Riedel shears serving as the primary surface guides for the planning of seismic profile acquisition.

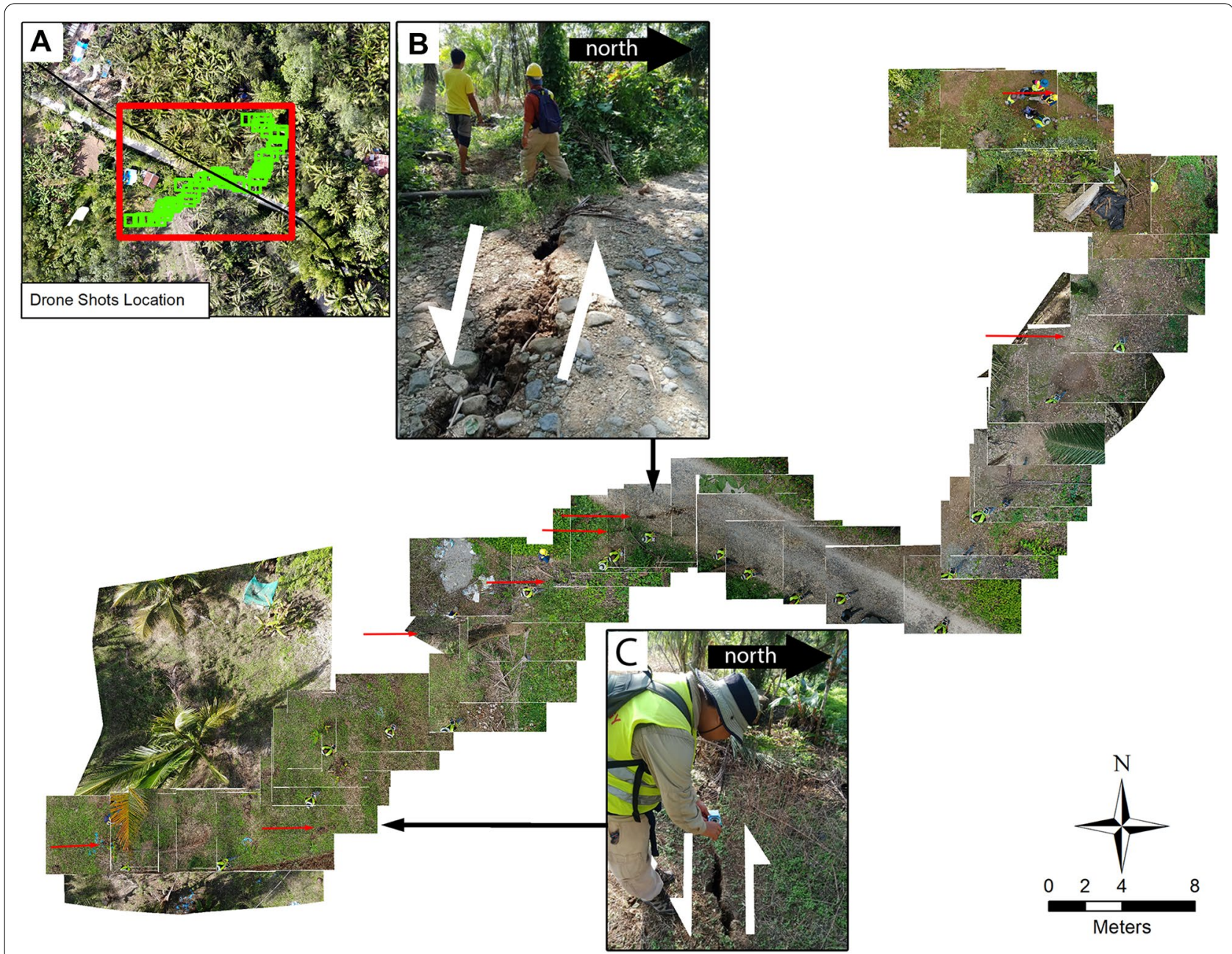

Fig. 9 Orthomosaic generated from low-altitude manual flight. Red arrows point to east-west trending Riedel shears 


\section{Taal eruption}

The 2020 Taal eruption deposited several centimeters of ashfall in the surrounding provinces of Batangas, Laguna, and Cavite with fissures being reported in the Batangas towns located to the southwest of Taal Volcano. Numerous volcanic earthquakes produced fissures reported in the Batangas towns located to the southwest of Taal
Volcano such as Lemery, Agoncillo, Calaca and San Nicholas where UAV surveys were conducted in these towns to image the fissures. Figure 10 shows one section of San Nicolas town with its ash-covered houses and roads flown from an altitude of $100 \mathrm{~m}$ above ground level. The individual average length of fissures captured by the UAV from San Nicolas town ranged from 2 to $5 \mathrm{~m}$, with

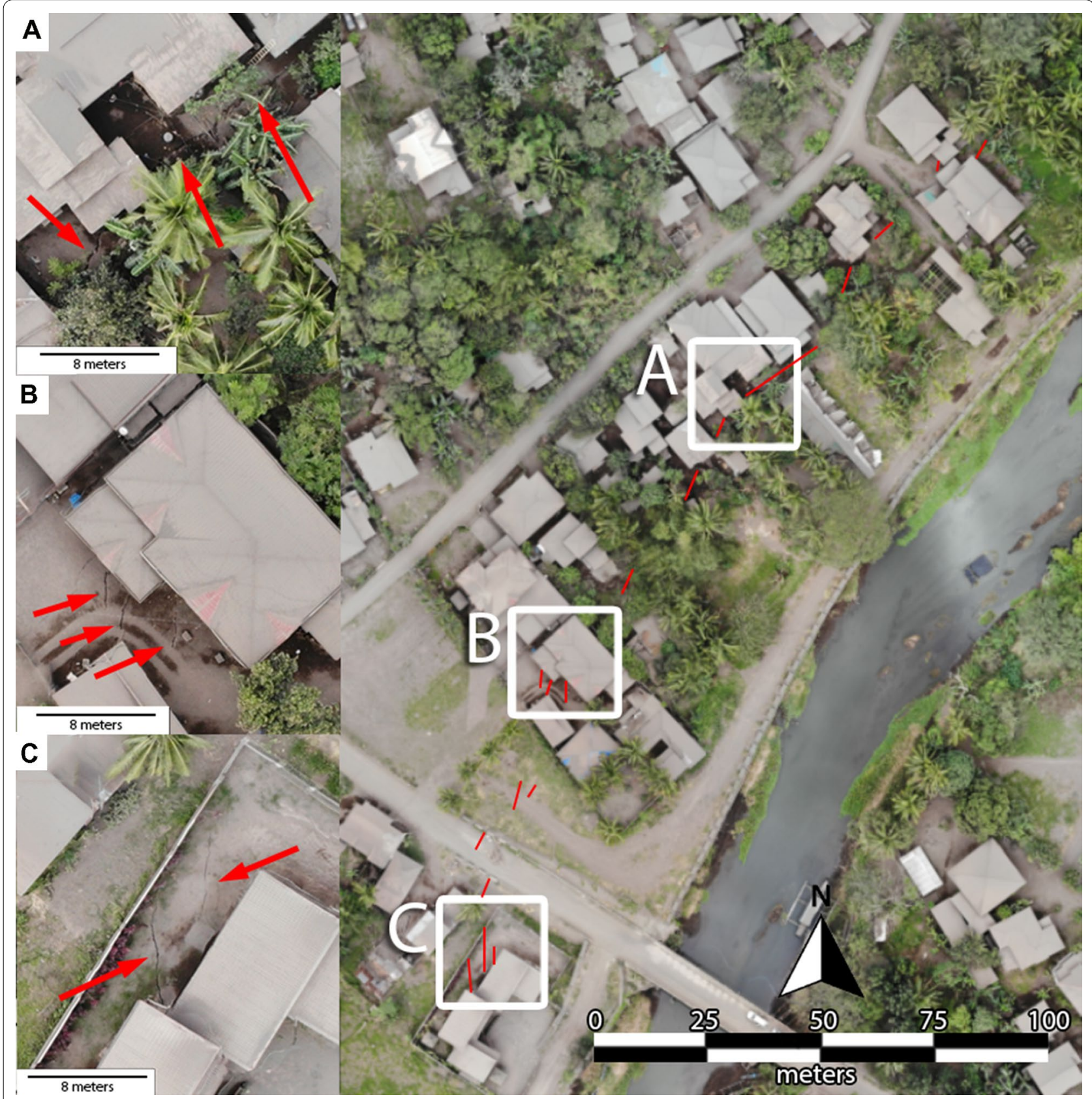

Fig. 10 Orthomosaic of ash-covered town crossed by northeast-trending fissures delineated in red. Insets $A, B$, and $C$ show some of the most prominent fissures (red arrows). The longest measured fissure in this zone, as visible from the drone imagery, is approximately $19 \mathrm{~m}$ (partially contained in inset A) 
the longest being $19 \mathrm{~m}$. The large area being investigated necessitated high-altitude flights to capture as large an area as possible while remaining within the danger zone and under the threat of an imminent eruption. However, despite the high-altitude flights, northeast-trending fissures were still captured by the drone flights, visible in insets A, B, and C of Fig. 10.

Light detection aperture radar (LiDAR) images from the DOST-UP DREAM and Phil-LiDAR Program (2019) show that the regional location of the fissures is characterized by morphological features suggesting horst-graben structures (Fig. 11). The fissures trended dominantly to the NE which could be related to the suspected volcanic rift zone straddling the Pansipit River trending NE (Aurelio et al. 2020).

Drone-aided mapping produced images of deformation related to these fissure zones indicating a NE-SW preferred orientation (Fig. 10). In other field-observation sites, very steep dips either directed to the NW or SE were found. The relative movement of blocks separated by the fissures is alternating upward and downward on adjacent blocks, consistent with a horst-and-graben structure. Measurements of as large as $2 \mathrm{~m}$, averaging about $0.3 \mathrm{~m}$ of vertical displacement were recorded.

Table 1 summarizes the different input cited in the workplan in Fig. 4 as applied in the three different disaster areas and as their corresponding products have been presented.

Apart from the immediate availability of data from drone deployments in post-disaster settings compared to other commonly used tools such as satellite-based remote sensing and plane-mounted radar such as LiDAR, the sub-centimetric resolution of the products and the ability to fly under trees, clouds, and other obstructions as shown in Fig. 9 makes drone surveying superior to these higher-altitude acquisition platforms. Furthermore,

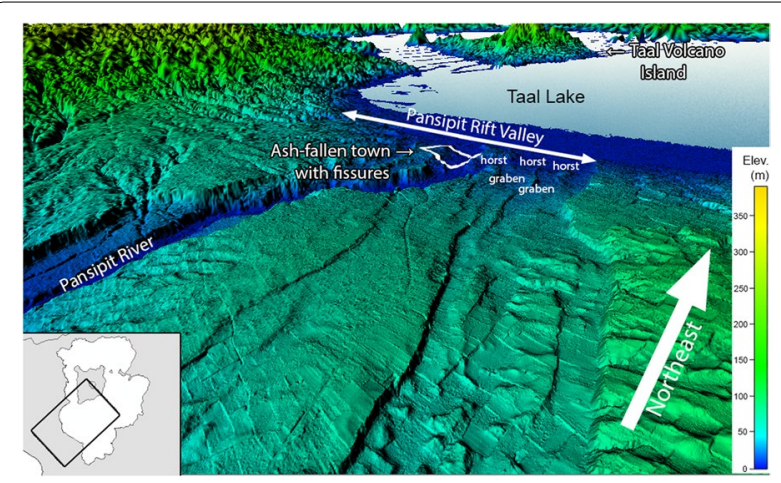

Fig. 11 LiDAR DTM of Pansipit Rift Valley. The rift valley is characterized by horst-and-graben structures upon which the town of San Nicolas sits. The coverage of Fig. 10 is shown the portability of these tools and the relatively lower cost to the commonly used alternatives make drone surveys more accessible to research and response groups that do not have the financial resources of aerospace agencies or aerial survey companies.

\section{Conclusion}

UAVs have proven to be useful, if not indispensable, equipment in the post-disaster assessment toolkit to gather data quickly and safely within the disaster-stricken zone. The investigative approach using UAVs for the three disasters successfully mapped lateral spreading on sloping ground such as old sedimentary rivers and dried wetlands, surface ruptures with the help of remotely sensed data over difficult terrain, and horst-and-graben structures in volcanic terrains. UAV-estimated displacements are in the same order of magnitude with centimetric accuracy. This strongly justifies use of drone surveys in areas that are not accessible, especially immediately after a geologic hazard hits a populated area and rapid science-based decisions are crucial in saving lives and property. Data collection for both scientific study as well as humanitarian response can be fulfilled by drones and a well-implemented and well-informed series of flight plans. These flight plans need to be adjusted on-site given constrains on time, accessibility, terrain and vegetation, and the size of the area of investigation. However, flight plan optimization for time and safety in a post-disaster setting must also ensure that the quality and resolution of surface data being captured meets the needs of scientists as well as disaster-response teams.

The varied formats of output that drone-collected imagery provide multiple possibilities for post-disaster analysis and preservation of ground surface deformations that have been observed in these post-disaster sites. These ground deformation features are often removed by subsequent human activity necessitating preservation in a digital format.

We presented a disaster-response UAV-deployment workplan in our study to guide researchers and first responders in the implementation of their own deployments in the event of disasters caused by geophysical hazards. Examples of implementation of this workplan in three different disaster events in the Philippines were discussed and their products and results consolidated for reference of others who would need to assess other postdisaster areas around the world. If followed, this workplan and the indicated drone settings may prove useful in optimizing data collection, ensuring the safety of the drone team and the drone itself, and generating data useful for both scientific analysis as well as humanitarian response and aid. 


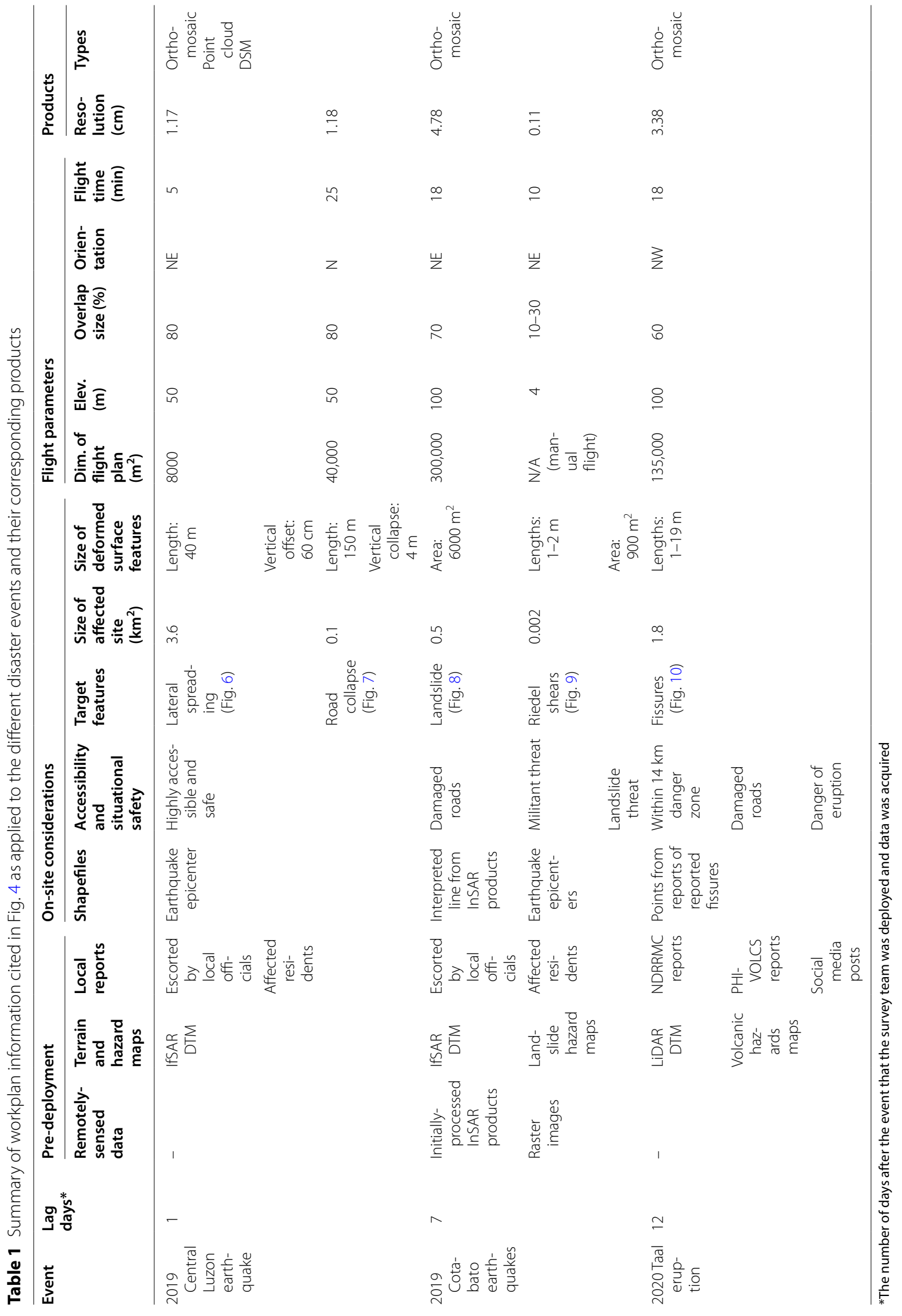




\section{Acknowledgements}

This research study was supported by University of the Philippines National Institute of Geological Sciences, University of the Philippines Resilience Institute, and Energy Development Corporation. The authors would like to acknowledge the local government units of Floridablanca, Pampanga, Makilala, Cotabato and Batangas province who provided logistical assistance as well as critical information on the location of the observed deformation features and phenomena. The authors would like to express their appreciation to the following laboratories/groups: UP RI NOAH Hazard Team, UP NIGS Volcano-Tectonics Laboratory, and the UP NIGS Structural Geology and Tectonics Laboratory. The authors would also like to acknowledge John Dale Dianala of Oxford University and UP NIGS for providing the initial interpretation of interferograms that guided the flight plans in Cotabato.

\section{Authors' contributions}

$\mathrm{RLY}$ is the main drone operator, image processor, and contributor to the manuscript. AABY is the secondary drone operator, provided supplementary field data and notes, and contributed to the manuscript. AMFAL provided overall direction in the mobilization and conduct of the fieldworks, provided specific targets for data capture in the field, and shaped the cohesive flow and thought of the manuscript. MAA provided critical technical input both in the observation and capture of features in the field as well as in the manuscript itself. All authors were present in the three post-disaster sites included in this study and observed together and individually the different features and phenomena discussed in this manuscript. All authors read and approved the final manuscript.

\section{Funding}

The field deployments to the disaster areas studied in this article were made possible by funding from the National Institute of Geological Sciences of the University of the Philippines, Diliman and with donations from UP Alumni through the UP Foundation Inc. Additional funding was provided by the University of the Philippines System through the UP Resilience Institute project "Pandemics, Compound Disasters, and Other Complex Emergencies".

\section{Availability of data and materials}

The datasets generated and analyzed during the current study are available on Google Drive: https://drive.google.com/drive/folders/1P71wa6BCsbYoeS uh0hkXcLd8CVT2d5UK. Use of these datasets can be cited as follows: "Ybanez et al., 2021 (this paper)".

\section{Declarations}

\section{Competing interests}

The authors declare that they have no competing interests.

\section{Author details}

${ }^{1}$ National Institute of Geological Sciences, College of Science, University of the Philippines, Diliman, 1101 Quezon City, Philippines. ${ }^{2}$ University of the Philippines Resilience Institute, University of the Philippines, Diliman, 1101 Quezon City, Philippines.

Received: 18 December 2020 Accepted: 8 June 2021 Published online: 15 June 2021

\section{References}

Aurelio M, Rafael DJ, Bermas A, Escudero JA, Ybañez R, Ybañez AA, Baldago C, Balangue-Tarriela R, Sarmiento DM, Trinidad JR, Lagmay AMF, Young A (2020) Taal 2020 ground fissures: indication of rift volcanism? In: Paper presented at Virtual GeoCon 2020, Manila, Philippines, 1-3 December 2020

Bato MG, Lundgren PR, Pinel V, Solidum RU Jr, Daag A, Cahulogan M (2020) The 2020 eruption and the large lateral dike emplacement at Taal volcano, Philippines: insights from radar satellite data. Geophysics. https://doi.org/ 10.1002/essoar.10504404.2

DJI (2018) Mavic air user manual. https://www.dji.com/mavic-air/info. Accessed 16 July 2020
DJl (2020) Mavic 2 pro/zoom user manual. https://www.dji.com/mavic-2/info\# specs. Accessed 16 July 2020

DOST-UP DREAM and Phil-LiDAR Program (2019) Taal Open LiDAR data. https://lipad.dream.upd.edu.ph/\#home. Accessed 18 Aug 2020

Ekström G, Nettles M, Dziewoński AM (2012) The global CMT project 2004-2010: centroid-moment tensors for 13,017 earthquakes. Phys Earth Planet Inter 200-201:1-9

Gomez C, Purdie H (2016) UAV-based photogrammetry and geocomputing for hazards and disaster risk monitoring - a review. Geoenviron Disasters $3(1): 23$

Greenwood F, Nelson EL, Greenough PG (2020) Flying into the hurricane: a case study of UAV use in damage assessment during the 2017 hurricanes in Texas and Florida. PLoS ONE 15(2):e0227808

Hungr O, Leroueil S, Picarelli L (2014) The Varnes classification of landslide types, an update. Landslides 11(2):167-194

Inoue H, Ohsumi T, Fukui H, Guragain R, Basyal GK, Chaudhary S, Adhikari SR (2016) Damage mapping of April 2015 Nepal earthquake using small UAV. In: Paper presented J-rapid-Nepal final workshop 2016, Ministry of Population and Environment (MoPE) and Japan Science and Technology Agency (JST), Kathmandu Nepal, 21-22 June 2016

Laurel D (2020) These images show the severity of the ashfall from Taal volcano's eruption. https://www.topgear.com.ph. Accessed 14 Jan 2020

Li B, Li Y, Jiang W, Su Z, Shen W (2020) Conjugate ruptures and seismotectonic implications of the 2019 Mindanao earthquake sequence inferred from Sentinel-1 InSAR data. Int J Appl Earth Obs Geoinf 90:102127

Mavroulis S, Andreadakis E, Spyrou NI, Antoniou V, Skourtsos E, Papadimitriou P, Kasssaras I, Kaviris G, Tselentis GA, Voulgaris N, Carydis P (2019) UAV and GIS based rapid earthquake-induced building damage assessment and methodology for EMS-98 isoseismal map drawing: the June 12, $2017 \mathrm{Mw}$ 6.3 Lesvos (Northeastern Aegean, Greece) earthquake. Int J Disaster Risk Reduct 37:101169

NDRRMC (2019) SitRep No. 03 re magnitude 6.1 earthquake in Castillejos, Zambales (situation report no. 3). National Disaster Risk Reduction and Management Council. http://www.ndrrmc.gov.ph/attachments/article/ 3754/SitRep_No_03_re_Magnitude_6point1_Earthquake_in_Castillejos Zambales issued_24April2019.pdf. Accessed 20 Oct 2020

NDRRMC (2020a) SitRep No. 39 re magnitude 6.6 and 6.5 earthquakes in Tulunan, North Cotabato (p. 6) [situation report]. National Disaster Risk Reduction and Management Council. http://www.ndrrmc.gov.ph/20incidents-monitored/3929-sitrep-re-magnitude-6-6-earthquake-in-tulun an,-north-cotabato. Accessed 20 Oct 2020

NDRRMC (2020b) Situational report no. 44 re Taal volcano eruption. Disaster Risk Reduction and Management Council. https://reliefweb.int/report/ philippines/ndrrmc-update-situational-report-no-44-re-taal-volcanoeruption-26-january-2020-0. Accessed 20 Oct 2020.

PHIVOLCS (2019a) Primer on the 22 April 2019 magnitude 6.1 Central Luzon earthquake (p. 3). Philippine Institute of Volcanology and Seismology. https://www.phivolcs.dost.gov.ph/index.php/news/8233-primer-on-the22-april-2019-magnitude-6-1-central-luzon-earthquake-23-april-2019. Accessed 20 Oct 2020

PHIVOLCS (2019b) Update on the 2019 Cotabato fault system earthquake series (p. 4). Philippine Institute of Volcanology and Seismology. https:// www.phivolcs.dost.gov.ph/index.php/news/9314-update-on-the-octob er-2019-cotabato-fault-system-earthquake-series. Accessed 20 Oct 2020

PHIVOLCS (2020a) Taal volcano bulletin. Philippine Institute of Volcanology and Seismology. https://www.phivolcs.dost.gov.ph/index.php/taal-volca no-bulletin-menu/9620-taal-volcano-bulletin-12-january-2020-07-30-pm Accessed 20 Oct 2020

PHIVOLCS (2020b) General location of fissures related to the January 2020 Taal volcano eruptive activity. Philippine Institute of Volcanology and Seismology. https://www.phivolcs.dost.gov.ph/index.php/news/9662-gener al-location-of-fissures-related-to-the-january-2020-taal-volcano-erupt ive-activity. Accessed 20 Oct 2020

Sharma G (2016) Armed with drones, aid workers seek faster response to earthquakes, floods. Thomson Reuters Foundation. https://www.reute rs.com/article/us-humanitarian-summit-nepal-drones-idUSKCN0Y7003. Accessed 16 July 2020 
Xu Z, Yang J, Peng C, Wu Y, Jiang X, Li R, Zheng Y, Gao Y, Liu S, Tian B (2014) Development of an UAS for post-earthquake disaster surveying and its application in Ms 7.0 Lushan earthquake, Sichuan, China. Comput Geosci 68:22-30

\section{Publisher's Note}

Springer Nature remains neutral with regard to jurisdictional claims in published maps and institutional affiliations.
Submit your manuscript to a SpringerOpen ${ }^{\odot}$ journal and benefit from:

- Convenient online submission

- Rigorous peer review

- Open access: articles freely available online

- High visibility within the field

- Retaining the copyright to your article

Submit your next manuscript at $\boldsymbol{\nabla}$ springeropen.com 